\title{
Literary Translation and Transmediality: Clive Scott's Reader-Oriented Translation Theory and Practice
}

\author{
Marko Pajević (Corresponding author) \\ College of Languages and Cultures, University of Tartu, Estonia \\ Email: marko.pajevic@ut.ee
}

Received: $10 / 11 / 2020$

Accepted: 14/01/2021

Published: 01/03/2021

Volume: 2 Issue: 2

How to cite this paper: Pajević, M. (2021). Literary Translation and Transmediality: Clive Scott's Reader-Oriented Translation Theory and Practice. Journal of Critical Studies in Language and Literature, 2(2), 1-10

DOI: https://doi.org/10.46809/jcsll.v2i2.53

Copyright (C) 2020 by author(s) and Global Talent Academy Ltd. This work is licensed under the Creative Commons Attribution International License (CC BY 4.0).

http://creativecommons.org/licenses/by/4.0/

\section{(c) (i)}

\begin{abstract}
The British translation practitioner and theorist Clive Scott has presented an approach to literary translation that integrates the transmedial into textual translation. His translations of poetry contain doodling, handwriting, crossing out, writing over, typographical experimentation, and photo-collages; he even offers photo-poetic translations consisting exclusively of photos. By including such extra-verbal matter, they play with the medium of literature and integrate a rich variety of visual forms. Scott wishes to stress the role of perception in translating; he offers a reader-focused theory of translation. He is much less concerned with translation as a service for people who do not understand the original language than with the act of translating as a school for reading and hence for developing our capacities of perception and self-awareness. The materiality of language plays a major role in such an idea of translation. His approach has little to do with intentional meaning, focusing instead on the accessibility of sense. Translating is a process, and it is the relationship of this process to what Scott rightly sees as the multi-sensory process of meaning-making during reading that is at issue in his theory and practice. By analysing Scott's theory and examples of his translationwork, this paper considers what this approach to translating says about transmediality in a phenomenological sense: it sheds light on how we read and perceive and on what the transmedial elements in these processes do. Scott's transmedial translation theory and practice bring to the fore the multiplicity of media involved in the perception of a text in the reader's mind and thus sharpens the awareness of what language is and does.
\end{abstract}

Keywords: Translation Theory, Multimediality, Clive Scott, Literary Translation, Reader, Perception

\section{Introduction}

This article investigates the role of transmediality in translation by analysing Clive Scott's recent theory and practice of translation. Translation, as Scott sees it, is by definition transmedial. His way of translating, in any case, exposes the multilingual and multi-sensory aspects involved in the act of reading and appears to suggest translation should make these psycho-physiological aspects of perception manifest. Transmediality therefore has vast potential to extend the field of translation and foreground its potential to make us more aware of the processes of perception and creation. 
Clive Scott is an eminent British scholar and translator in French Studies and Professor emeritus at the University of East Anglia with its prestigious British Centre for Literary Translation. He is highly esteemed as a leading scholar in French poetry and literary translation. Two decades ago, literary translation became his chief focus, resulting in several publications with Cambridge University Press and Legenda, top-ranking British publishers, with a peak in 2012 when two books appeared simultaneously. It is from these that I will draw the most in this article: Literary Translation and the Rediscovery of Reading (2012a) and Translating the Perception of Text. Literary Translation and Phenomenology (2012b).

I offer this information on Scott's standing in the British academic community (and the Anglophone world more generally) partly to anticipate a reaction to his work that he himself addresses: the temptation to dismiss his ideas as ludicrous or, at any rate, not really about translation at all. One of the objectives in what follows is to demonstrate why Scott's reflections on translation, while certainly representing an extreme case, not only help to understand what translation is actually doing, but also add something to the practice of translation, with transmediality playing a major role in this contribution. It may be useful, at this point, to present an example of his translationwork without any further introduction:

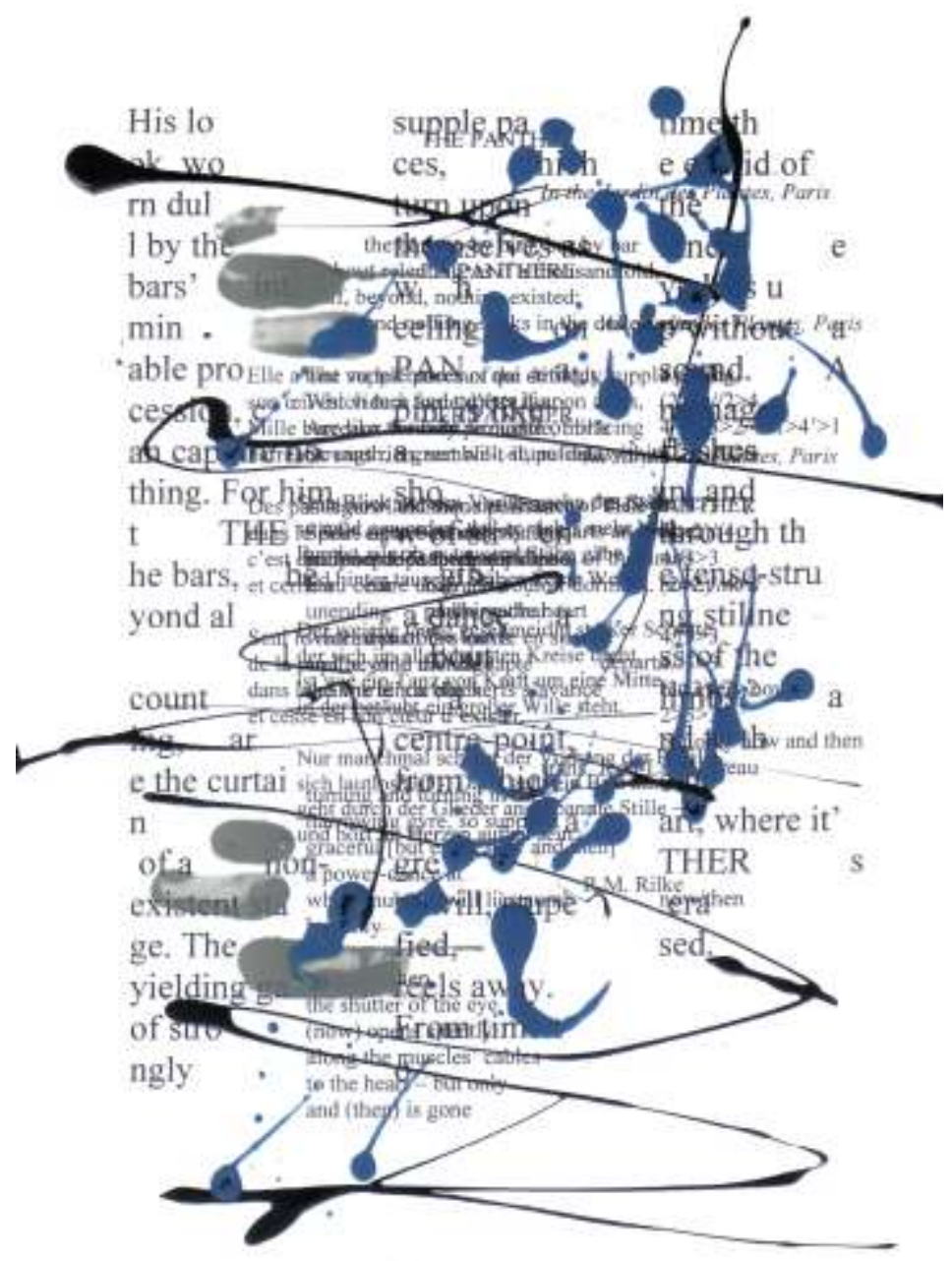

(Scott, 2012b, p.79)

Indeed, Scott suggests speaking of translationwork or translationsplay rather than simply of translation (Scott, 2012b, p.134). The above translationwork is on Rilke's Der Panther. The German source text (ST) can perhaps still be discerned in the middle block, but it is overwritten and accompanied in various ways. Before arriving at this result, Scott had first written a subjective and impressionist translation with insertions of onomatopoetic sound-writing of the panther's footsteps (pad pad pad), stressing certain patterns in a second column. In the following versions he kept closer to the ST but performed an interrogation of some formal features, which he then manifested in writing the poems in three columns. These former versions feed into the version shown above, which, in a further version, gets overprinted with calligraphic exercises (Scott, $2012 \mathrm{~b}$, p.77-80). The proliferation of versions is a core feature of Scott's theory since the ST is considered to be a departure for readers and the target text (TT) a manifestation of their individual, potentially endless transformative readings.

This procedure evidently contains transmedial elements with the graphic aspects and the doodling. Why does Scott proceed like this? What could this tell us about translation, or rather, about the activity of translating? In presenting his theory more systematically, I will pursue these questions. 


\section{Translating for the Polyglot Reader}

First of all, I need to establish what Scott attempts to do: clearly this approach is about literary translation, with a focus on translation of poetry, and he considers this to be "the maximization of the literary, understood as the created excess of the signifier over the signified' (Scott, 2018a, p.245). So translators for him are not at all secondary service providers. What they do, when they do it the way he propagates, is on the contrary 'at the forefront of experimental writing' (Scott, 2000, p.14). It is the creative, subjective aspect that Scott emphasizes, and he very much advocates foreignizing translations, referring to Venuti's term in the tradition of Pannwitz and Benjamin (Venuti, 1995), yet radicalizing it to the extreme by taking it to the level of the reader.

Scott even suggests that literary translation should dissociate itself from translation studies altogether (Scott, 2012a, p.9), claiming that that field has so far failed to develop a theory about the literariness of the translational act itself and even to incorporate literary theory (Scott, 2012a, p.10). He wants literary texts to be translated into their literariness. By this, he means that the literariness does not reside in qualities inherent in a text that could be rendered more or less well in another language (metaphor by metaphor, alliteration by alliteration), but he sees the literary rather as 'something experienced and bestowed on the text by a reader' (Scott, 2012a, p.9). Or, more explicitly, 'The literary lies in the excess of the signifier over the signified, and that excess is created by literature's maximisation of the materiality and conceptuality of language, so that both the body and the psyche of the reader are maximally involved.' (Scott, 2012a, p.166) This has little to do with translation as a professional service for readers who otherwise have no linguistic access to the ST. Scott rejects the general understanding of translation as interlingual translation, that is, as the translation of a source text in one language into a target text in another language. For him, the 'principal concern' of translation is 'to increase the circulation of languages and to sharpen our awareness of the inbuilt problematics of language and linguistic transfer' (Scott, 2012a, p.1).

Scott reiterates his decisive rejection of the idea of translation for the monoglot reader, as he terms it. He wants to free translation from this "stranglehold" because for him, it perpetuates visions of the frontier between languages instead of a shared space to be occupied. The monoglot reader cannot inhabit the contact zone of 'the dialogue between ST and TT'. What is important for Scott in his practice of, and reflection on translation is rather 'a philosophy of translation" where he sees translation as 'an agent of consciousness and being-in-the-world' (Scott, 2018a, p.8-9). He explicitly intends 'a pursuit of self-enquiry and self-discovery by the reader' (Scott, 2018a, p.2) in the process of translation, which, for him, is not about preserving the ST but about 'setting the ST in motion' (Scott, 2018a, p.8). This also serves a 'self-dynamization' (Scott, 2018a, p.89) such that he can state, 'translation's main object is to reconfigure consciousness' (Scott, 2018a, p.107). From this perspective, translation is indeed for people who can compare the translation with its source. Translation is then a means of manifesting cognitive processes in the reading process. To this end, intralingual and intermedial translation are more fruitful.

Scott compares his enterprise to what has been done in music and painting and refers to the collection of the 25,000 cover versions inspired by Gershwin and Heywards' Summertime, in all musical styles imaginable, or Picasso's forty-four explorations of Velasquez's Las Meninas. With such practising artists in his sights, he wants to promote translations by 'practising readers'. Since we do not yet have such a concept, he states, he wants to create and examine it (Scott, 2018a, p.14).

As the book titles I mentioned earlier indicate, Scott's approach is phenomenological: it is about the perception of a text, which means that it is primarily about the reader. Scott's inquiry zooms in on the translator as reader. He embraces the position that 'translation is a mode of reading which gives textual substance to reader response; reading is reading-totranslate.' (Scott, 2012a, p.10) It is evident that a shift takes place between the text and the processing of the text in a reader's mind:

Translation is the act by which we reveal to ourselves, and to other readers, what a text has made available to us in terms of linguistic experience and the renewal of perceptual consciousness. Clearly, this experience and renewal of consciousness are not evident in the source text, since it is only through the reader that they come into being: in translating the source text, the reader is translating his/her readerly experience into existence. (Scott, 2012a, p.XX)

This is clearly quite a one-sided position, inversing traditional views and neglecting the text in favour of the reader's subjectivity. The text here is a starting point for a never-ending process of transformative readings, which all become parts of the text. This process can be compared to the Jewish tradition of Talmud-readings, where the question of origin gets lost in the processuality of readings. In Hebrew, the reader must very actively fill in the gaps since vowels are not spelt. This tradition has had a considerable impact on postmodern textual theories, particularly through thinkers such as Levinas (cf. Levinas, 1968).

Scott, however, takes literary criticism to task for blocking out an interpretation of readers' personal idiosyncrasies, their associations, memories, intertexts, all the 'autobiographical input' (Scott, 2012a, p.2). Traditionally, we indeed behave as if the translator is Mr Nobody. It was Venuti who debunked the 'invisible translator' twenty-five years ago (Venuti, 1995). There is no neutrality in language and the decisions we take in translating are very much subjective ones. By foregrounding the reader in the translation process, Scott thus proposes two shifts: instead of textual examination, he advocates readerly 
consciousness; instead of post-reading critical retrieval of a text, he advocates in-reading readerly response to it (Scott, 2012a, p.2). Scott attacks the perception of the source text as static, insisting that it consists actually of its composition period, its reception life and its changing existence and becoming in the individual reader's mind (Scott, 2012a, p.3). Consequently, translating is a condition of reading and an endless one, at that. When looking at the reading process, he focuses on the 'entirely personal enterprise of alterity' and the transformation process of other into self (Scott, 2012a, p.4). This focus on the biographical input of reading, then, makes of translation 'a form of experimental writing', with widely varied and shifting multi-sensory parameters (Scott, 2012a, p.4). Consequently, Scott calls for an expansion of 'translation's own language' by developing visual paralanguage and alternative graphics, ranging from typography and layout to handwriting, doodling, painting, and crossing out. All of this stresses the textual performance in and of the text (Scott, 2012a, p.5), and it leads to proleptic multiple and multi-sensory translations (Scott, 2012a, p.10). Transmediality is thus an inherent element of this approach to translating.

In one of his definitions of translation, Scott calls it 'the act by which we reveal to ourselves, and to other readers, what a text has made available to us in terms of linguistic experience and the renewal of perceptual consciousness' (Scott, 2012a, p.XI). Since these things become manifest only via the reader, he wants to rediscover reading for literary translation (see again the title Literary Translation and the Rediscovery of Reading, 2012a). They are less present in the ST, but 'the reader is translating his/her readerly experience into existence'. Translation indeed becomes 'a way of discovering how we read, and of enhancing reading' (Scott, 2012a, p.10). The experience of reading is literally written into the translation (Scott, 2014, p.1).

Scott considers reading 'an existential and bodily encounter with the text' (Scott, 2012b, p.XI), which is why he wants to establish the materiality of language as the standard means of translation, that is, elements such as handwriting, overwriting, crossing out, doodling, typography. This would, he claims, establish a new and particular form of literariness. Translation would be a distinctive form of literary writing and of literature (Scott, 2012b, p.15).

In order to underline the crucial role of the reader in this encounter of text and translator, he builds on Merleau-Ponty's phenomenology: 'We translate psycho-physiological perceptions which derive from a source text into a target text which embodies those perceptions' (Scott, 2012b, p.XI). That means that it is our consciousness that is decisive for what happens in the encounter with a text. Literary translation, on this view, is 'the translation of the writer's style into the reader's style, or, put another way, translation is the exchange of consciousness, a dialogue of perceptual behaviours' (Scott, 2012b, p.XII). The personal relation of the translator as reader with the text is key; it is a dialogical conception of translation.

In this conception, the hermeneutic side, the intention-to-mean in Gadamer's sense, steps back to give way to the availability-of-sense (Scott, 2012b, p.3). Translation is, then, regarded as a process, an activity in the mind. It becomes 'the process of reading performed', which is necessarily contingent (Scott, 2012b, p.5). This activity has to take place in the translated text. The stress lies here on the 'linguisticity' of the text, a language-medium (Scott, 2012b, p.10). The 'informational service' for those ignorant of the source language plays practically no role anymore. What counts, is the circulation of languages and the enrichment of the text through various languages. As literature results from the raw material of the world, the translation results from the raw material of a text (Scott, 2012b, p.11/15). Scott's form of translation is not bilingual and linguistic, rather it is 'multilingual and multi-sensory'. It intends to represent an 'existential involvement with the text' (Scott 2012b, p.20). He emphasizes 'not only that it is a translation's business to open up differences, rather than defend an exclusive singularity, but that translation enable the reader to inhabit several worlds at once' (Scott, 2012b, p.26).

Translation in this form enables an extension of our perceptual capacities (Scott, 2012b, p.35). Scott concludes that it is less about minimizing incomprehension than about releasing the ST, as other, into our world (Scott, 2012b, p.38) to enrich it.

The object is not to replace the ST in the target language but to interact with the ST in a way that takes it seriously as a partner in dialogue. Scott uses terms such as 'reciprocity' and 'answering' the text (Scott, 2012b, p.43). His concern is 'the inaugurative power of language' (Scott, 2012b, p.52) and he sees the translation as a point of departure, not of arrival (Scott, 2000, p.70). Such translations are evidently different from the ST. They enrich and re-activate it (Scott, 2012b, p.178). The translation's business, for Scott, is 'to give me a vivid sense of our dual participation in the world, a world constituted intersubjectively' (Scott, 2012b, p.179). That is what he calls 'a cooperative venture' of ST and TT (Scott, 2012b, p.180).

Due to the individuality of perception, there is in translation a 'coherent deformation' (Merleau-Ponty) of perception that we learn to inhabit while translating. Scott turns against a simple understanding of the sign in translation by strengthening the signifier over the signified. The signified is insufficient for understanding all the complex ways a reader makes sense of what she or he reads. With the example of the French 'elle rougit' translated into English as 'she blushes", Scott shows how such expressions can work very differently in the two languages on the level of sound, sound formation and its associations, with the result that despite the equivalence in the dictionary the signifier transports very 'different coordinates of consciousness, different experiences of facial behaviour' (Scott, 2012b, p.63). For him, 'translation is not a translation of the signifier into the signified, but of the signifier into another signifier' (Scott, 2012b, p.63). ${ }^{1}$ That means that we have to free ourselves from the idea of equivalences of meaning, since meaning comes about in so many different ways and not only via denotations. Language, Scott suggests, is not about using signs to pass on information: 'Languages and its senses are not information but in formation', and he calls this a 'restless and ramifying dynamic' (Scott, 2018a, p.16). He wants 'a new poetics of the signifier', to free the signifier from the constraint of meaning, the signified, to let it 'reinvent meaning out of its own metamorphoses' (Scott, 2018a, p.130). 
When he speaks of a multilingual translation, he refers to the multiple languages within any language, that is, 'textual languages', including presentation and projection. This performance of a text also includes the 'languages of the page' (Scott, $2012 b, p .133$ ) such as typography, fonts or doodling. This is a way of developing a 'productive relationship with language' and its energy (Scott, 2012b, p.183) - he refers here to Humboldt's famous definition of language not as product (ergon) but energy/activity (energeia) (Humboldt, 1903-36, VII, p.45).

The reader is always translating, Scott claims, since all readers incorporate associations and responses into the reading process. Translation is therefore useful to 'express and give shape to their encounters with the text' (Scott, 2012a, in jacket). Translation thus tells us a lot about how we read and enhances our reading (Scott, 2012a, p.10). For Scott, the linguistic experience of text, reading, is not limited to language, but it consists of, or activates, a sequence of sensations. Reading is a 'whole-body experience' and exceeds concepts and interpretation - it is cross-sensory and consists of psycho-physiological responses to words, grammar, syntax, typographic phenomena (Scott, 2012a, p.11). In translating, we can insert these responses, our reading, back into the text (Scott, 2012a, p.12). So he can assert, 'the function of translation is to individuate, in the here and now, the translator as reader, and to feed that individuation, that individual voice, back into the ST.'

Scott draws on Jerome McGann's distinction between hermeneutic reading and constructivist reading (McGann, 1991) and applies constructivist reading to his translation theory: it considers language as always in progress and uncontrollable, as a living organism. Looking at language this way, it is not a vehicle for a meaning outside itself, but 'a material performing its own body and expressive resourcefulness, encouraging us to savour its generative diversity.' (Scott, 2012a, p.15) Translation is the possibility of doing that to a maximum. Language seen this way is manifold: a text contains multiple languages. Scott lists presentation, projection, diacritical marks, punctuation, typefaces, layout, graphisms, voicing (Scott, 2012a, p.16), and adds the 'verbal paralinguistic' elements tone and intonation, tempo and pausing, volume and degrees of stress, as well as the 'visual paralinguistics' typeface, layout, letter shape, margins, the graphisms of calligraphy, space, elements of book design, paratext, the posture and gestures of a performer (Scott, 2012a, p.31). ${ }^{2}$ The 'existential involvement with text' is what he wants to enact with his approach to translation (Scott, 2012a, p.16).

Much of this serves to show that the medium of language is actually multimedial, bringing out its richness and potential. The visual of a text is a means of making the vocal apparent and of showing how to introduce the spoken into the written (cf. Scott, 2012a, p.36/107). Scott says à propos of doodling, for instance, that 'a graphic style is the gestural equivalent of the physiology of the voice'. (Scott, 2012a, p.28)

Since Scott considers the transformation of a text into a new typography 'a significant translational act' (Scott, 2012a, p.99) and translating means to write yourself as a reader/translator back into the text, for him translation is about the 'opening-up of new linguistic territories and cohabitation'. It is explicitly and intentionally about transforming the ST. Inspired by Walter Benjamin, he calls this the survival model of translation, as opposed to the transmissional model, since it projects the ST forward and widens its possibilities, 'giving the ST new options on ways of being' (Scott, 2012a, p.102).

That means translation is not an interlinguistic service for a monoglot reader but rather a readerly inscription and transformation, using all available media, to enrich the ST and to make it live on in a different context, relocated and transformed. The reader can accomplish this for him- or herself or for a community of polyglot readers, who can then read the translation together with the ST, exploring new facets in the process.

\section{Scott's Translationwork: Reading as Translation}

As a consequence of this idea, Scott also 'translates' English texts into English. And since this fact further underlines that this form of translation is transmedial, I will now focus on a translationwork as an example of what Scott achieves with his constructivist reading, that is, reading as translation. It is a rendering of the poem Adlestrop by Edward Thomas.

\section{Edward Thomas: Adlestrop}

Yes. I remember Adlestrop -

The name, because one afternoon

Of heat the express-train drew up there

Unwontedly. It was late June.

The steam hissed. Some one cleared his throat.

No one left and no one came

On the bare platform. What I saw

Was Adlestrop - only the name

And willows, willow-herb, and grass,

And meadowsweet, and haycocks dry,

No whit less still and lonely fair

Than the high cloudlets in the sky. 
And for that minute a blackbird sang

Close by, and round him, mistier,

Farther and farther, all the birds

Of Oxfordshire and Gloucestershire. (Scott, 2012a, p.16/ Longley, 2008, p.51)

Scott first observes that one could interpret the poem as being about an unexpected jolt out of functional time into inner duration, or about language, where the proper name Adlestrop contains the entire poem and is endowed with flora and fauna, memory and associations. He notices things such as the enumeration of nouns without articles, that is, unspecific objects rather in the realm of memory and imagination, referred to in non-syntactical language. He further points out Thomas's resistance to the use of the obvious rhyme word 'stop' - this allows the name to cultivate its own field of acoustic association, lying within the prosodic pattern afternoon/ willow-herb/ meadowsweet/ haycocks dry/ all the birds/ Oxfordshire etc. Scott's conclusion is that the text performs its meaning. So its meaning is less accessed by analysis than by the reader's body that is invaded by its sounds, rhythms, respiratory patterns and psycho-physiological impulses (Scott, 2012a, p.16-19). Then he offers his first version:

\section{ADLESTROP}

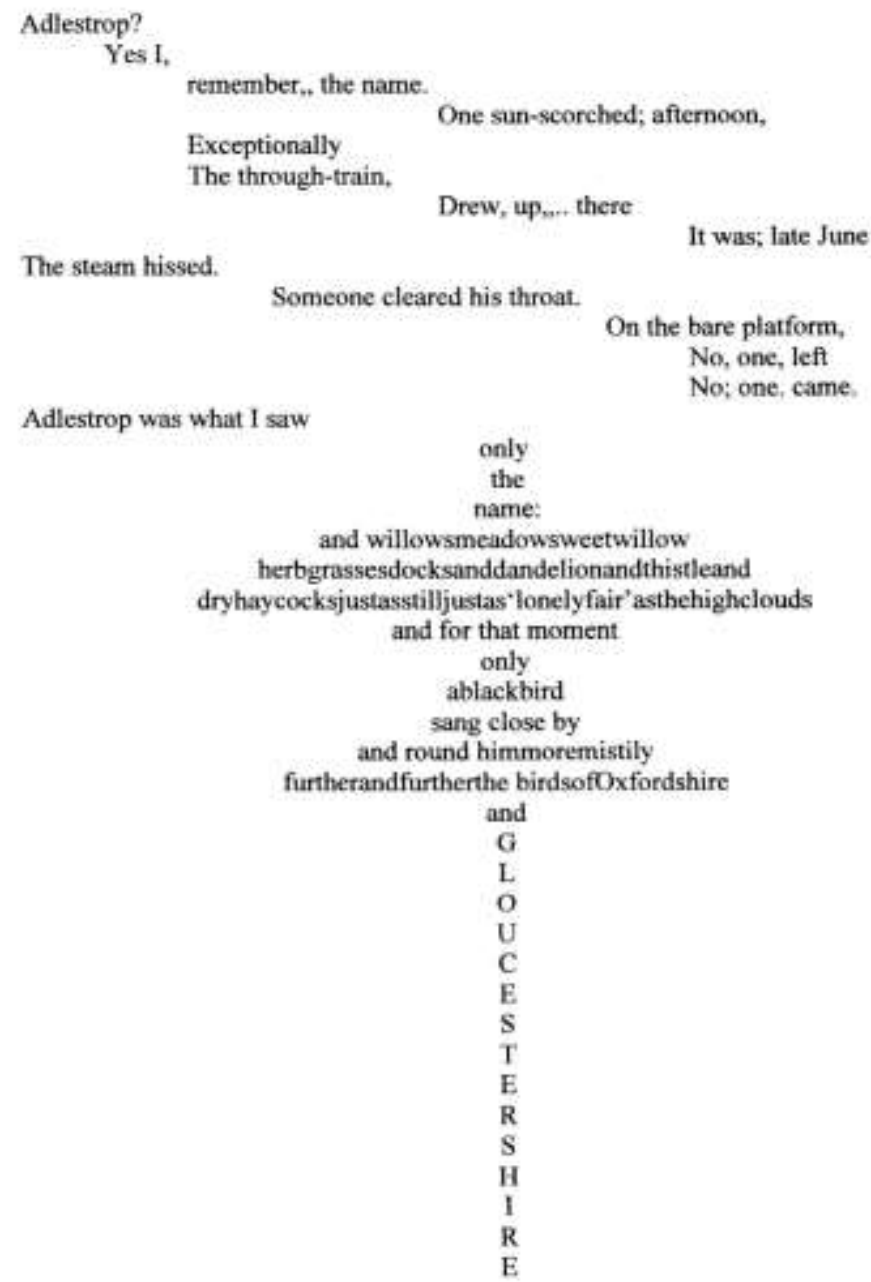

(Scott, 2012a, p.20) 
His 'translation' focuses on the typographical layout, stressing that this enacts a different model of human consciousness, so he translates it into his consciousness. That involves multiplying the margins in the first two stanzas to exacerbate the sense of disorientation. The capitalisation of all the segments, apart from 'remember', is intended to manifest the attempts to regain control of the utterance. The punctuation is increased and destabilised to perform the rupture of chronometric time. The last two stanzas are in scriptio continua, that is, without spacing between words, to express unbroken consciousness or the stream of the unconscious. He has added to the enumeration and used a medial axis to demonstrate a sinking of consciousness into experience. This symmetrical layout suggests a calligramme or a Rorschach test, and the poem takes the shape of a dragonfly, since Thomas's thought darted straight into his soul like a dragonfly, as he claims (Scott, 2012a, p.21). We can summarize that for Scott, his constructivist reading of Thomas is a reading of his own reading (Scott, 2012a, p.21), becoming aware of it in this manifestation of how he reads the poem, mainly by strategies of layout.

For the second version he adds his readerly associations, 'radial reading', as he calls it: one allusion to Proust where Marcel describes the memory of a very similar experience triggered by a spoon knocking against a glass reminding him of the hammer against the wheel of a train, and other allusions to bird songs and the Latin names of these birds. Quite deliberately he even adds the song of a gull to expand Thomas's circumference (Scott, 2012a, p.22-23), in spite of the fact that this maritime bird could not have been in Adlestrop. He reminds us that reading aloud is a physical tasting of language, engaging our body in the articulation - tongue, lips, teeth, palate - with fricatives, plosives, affricates, approximants, a 'language of the zoo (...) we keep in our buccal cavities' (Scott, 2012a, p.23). It is not easy to see how to read the result, but it is for each reader to decide what to do with it:

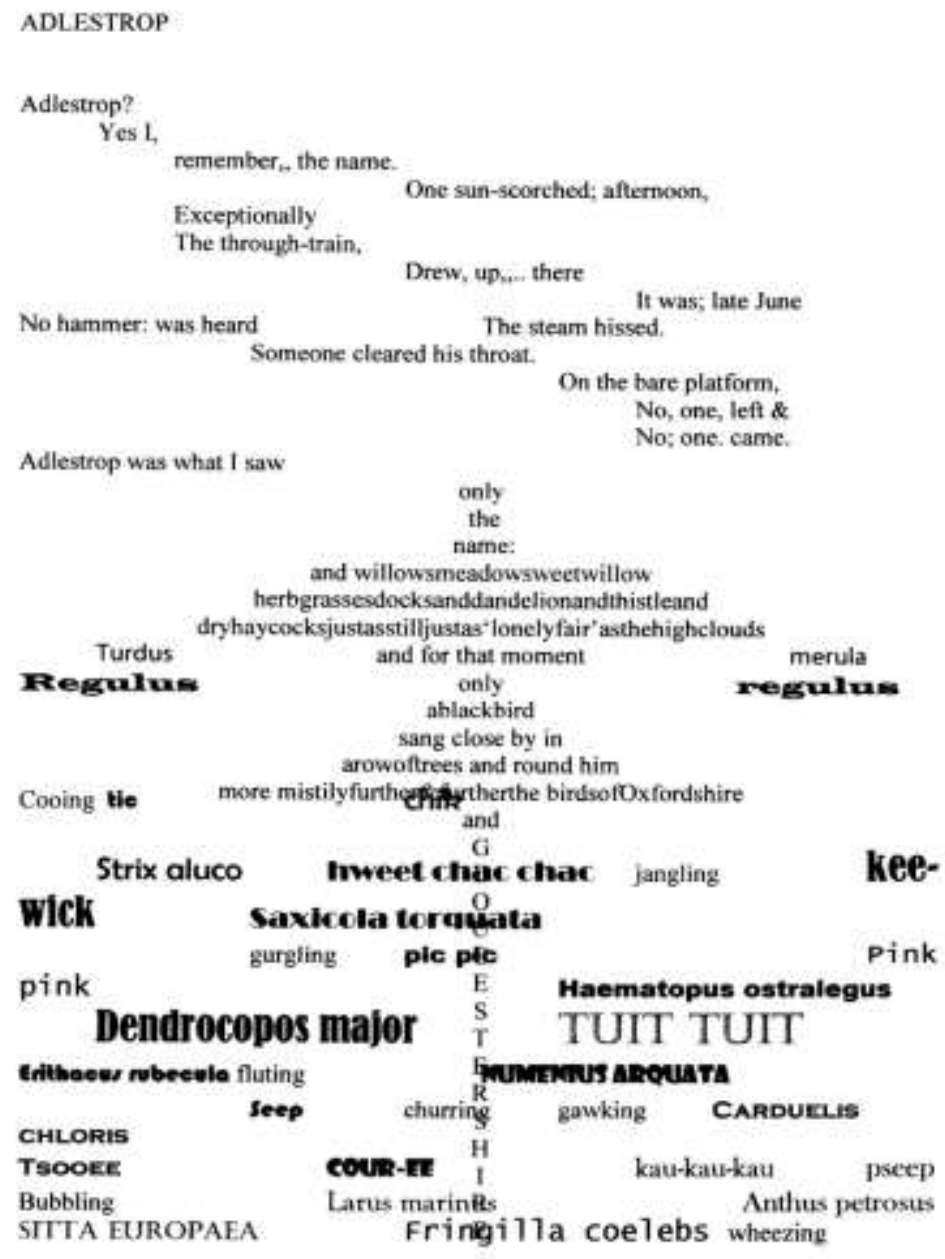

(Scott, 2012a, p.24) 
By using typeset and fonts to make rhythm visible, Scott urges, 'We have to re-imagine the participatory arts of the eye and the ear, and exercise them in our reading and writing with a physical immediacy we are unaccustomed to.' (Scott, 2012a, p.143) All these strategies are employed to make us aware of the individual dynamic multisensory aspect of the reading experience (cf. Scott, 2012a, p.30). This practice intends to cultivate also a new kind of listening in this widened awareness of language, that is, listening to the dynamics of the signifiers, not of the signifieds (Scott, 2012a, p.86).

A third version of Scott's translationwork on Adlestrop then prints the second version on music paper, on which he has drawn a sequence of calligraphic dance figures that could inspire a performer of the poem:

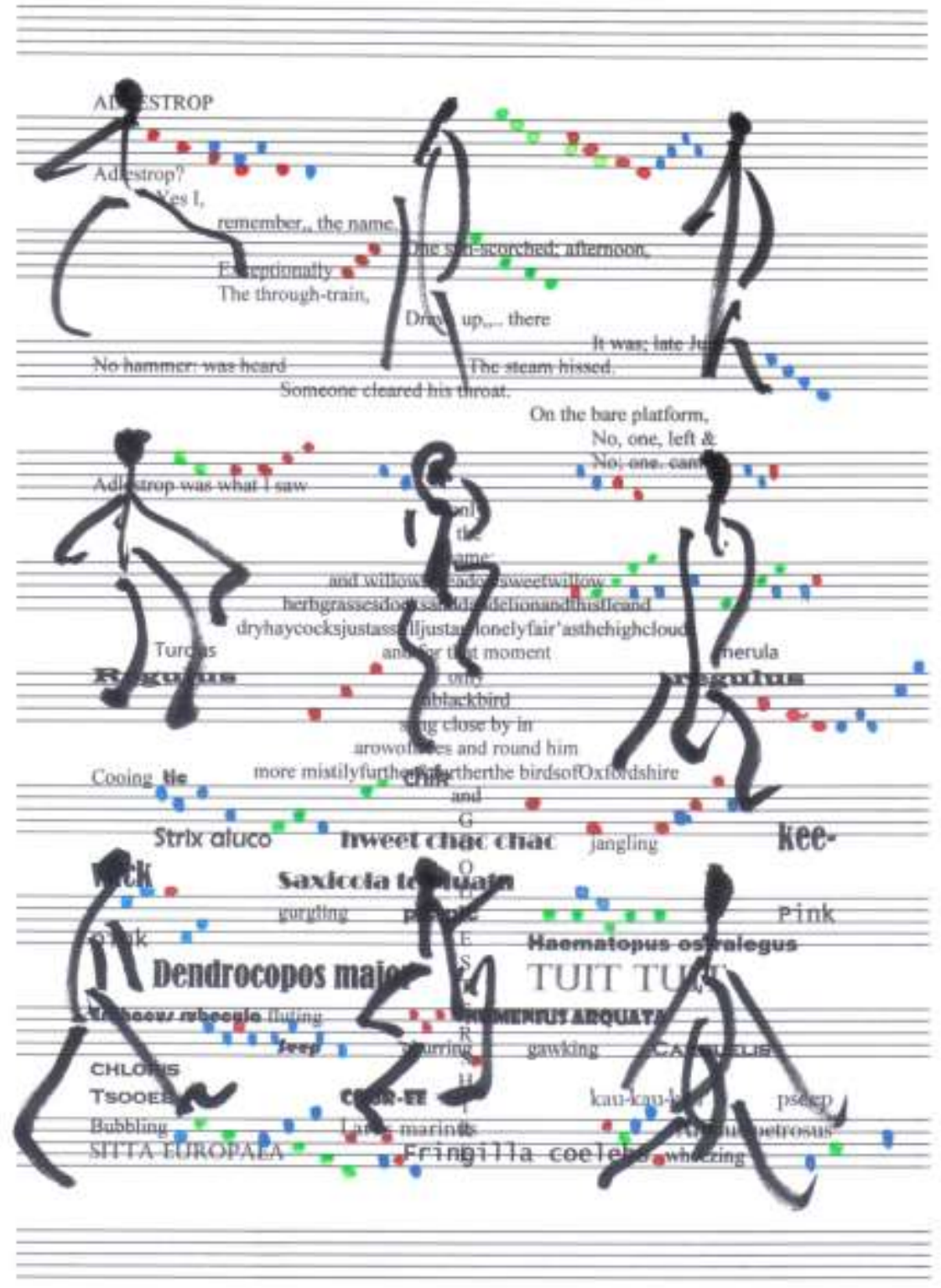

(Scott, 2012a, p.101)

Scott pushes the logic of his approach to translation even farther to a purely visual paralinguistic rendering, by translating a poem into photographs. He claims that by doing so, the images can, by their very arrangement, continue to project the modalities of the words. He urges that more attention be devoted to such wordless photo-poems as translational genre. Here is an example of his photopoetic translation of Apollinaire's Zone: 


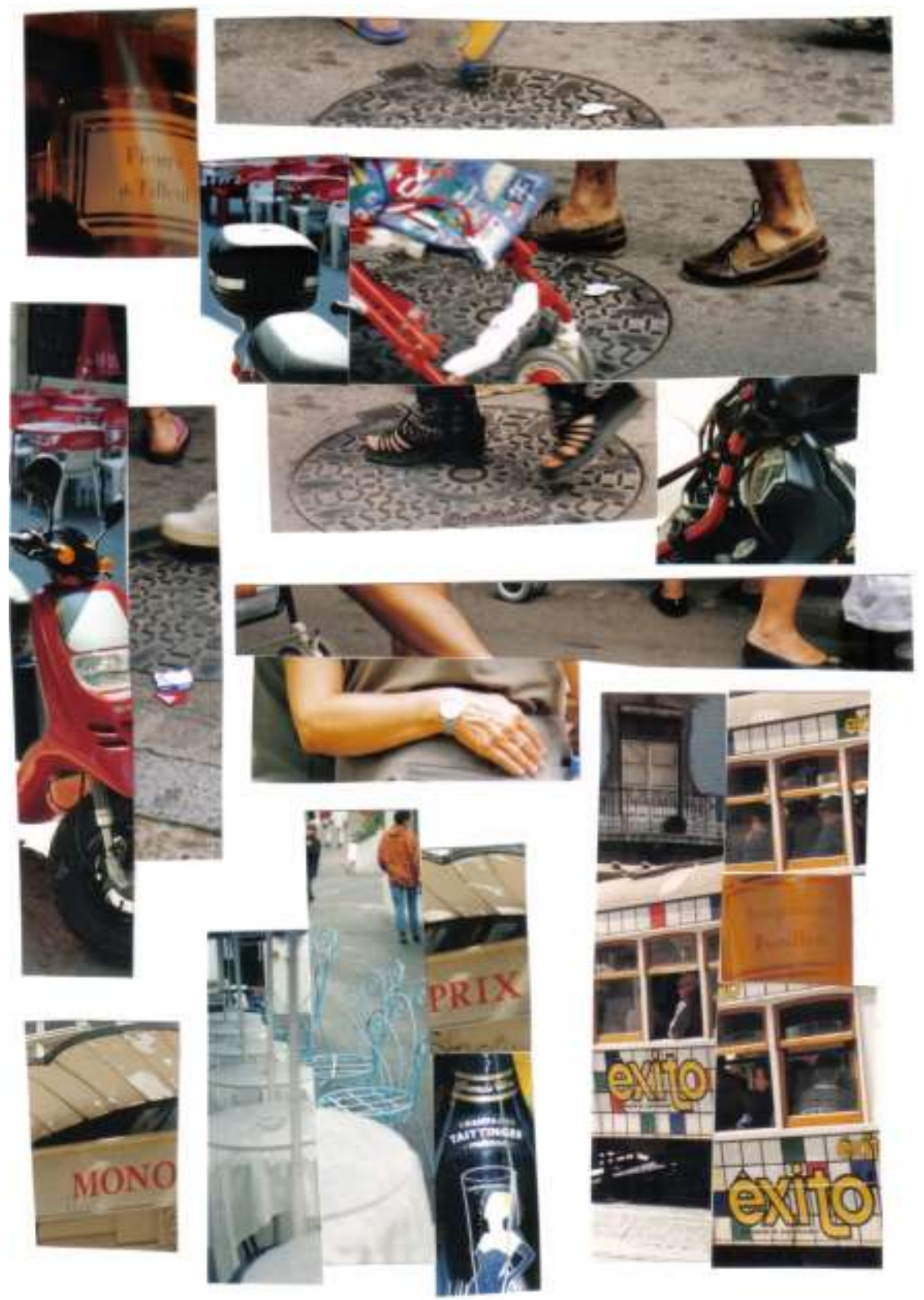

(Scott, 2012a, p.163)

With all these techniques, Scott puts the focus on the materiality of language. His translations are about performance and embodiment (Scott, 2012a, p.165). Not only are they ways of injecting the translator's body with its perception into the text, they also look at the body of language, sound and visual forms in their performance. In these processes, 'the reader's body is the point of intersection between, on the one hand, the inside world of the text and the energies it lets loose in the reader, and, on the other, the outside world which provides the context of reading and which both infiltrates, and is marked by, that reading.' (Scott, 2012a, p.168) This triggers creativity. Scott's translations are not aiming at a recuperation of the ST, but they are its 'generative perception' (Scott, 2012a, p.183). For this, all resources and media are multiplied and activated in view of his final objective, "some kind of "total translation"” (Scott, 2012a, p.186). ${ }^{3}$

\section{Conclusion}

In conclusion, Scott's theory and practice are transmedial in that they bring to the fore the multiplicity of media involved in the perception of a text in the reader's mind. Language is much more than neutral symbols for signifieds that we can assimilate purely intellectually. Language is what it is in its specific form, at each moment, and may contain sound, voice, and all the complex individual ingredients of perception, shaped by subjective experience with all sorts of associations, implying any and all of our senses. 
Is an effort to make all of this explicit still translation? Certainly not in the traditional sense of equivalence. Yet it does promote an awareness of the transfer that always takes place in translating, and it cultivates our awareness of our processes of perception of text, of reading. As a result, it may well provide translators with new resources with which to increase their understanding of their task and improve their work. Scott's approach cannot replace other forms of translation, nor is that his intention, but it is a useful and intriguing extension of the conception of translation that, via its transmedial components, broadens and deepens our awareness of what language is and does, and of what we are doing when we read and translate.

\section{References}

Humboldt, W. (1903-36). Gesammelte Schriften, Werke. Vol. VII. Berlin, Germany: Behr

Levinas, E. (1968). Quatre Lectures Talmudiques. Paris, France: Minuit

Littau, K. (2011). First Steps towards a Media History of Translation. Translation Studies 4(3). 261-281

(2016). Translation and the materialities of communication. Translation Studies 9(1). 82-96

Longley, E (ed.). (2008). Edward Thomas: The Annotated Collected Poems. Tarset: Bloodaxe Books

McGann, J. (1991). How to Read a Book. In The Textual Condition. Princeton, NJ: Princeton UP. 101-28

Meschonnic, H. (2011). Ethics and Poetics of Translating, trans. by P-P. Boulanger. Amsterdam/Philadelphia: John Benjamins

Pajević, M. (ed.). (2019). The Henri Meschonnic Reader. A Poetics of Society. Edinburgh, UK: Edinburgh University Press

Scott, C. (2000). Translating Baudelaire. Exeter, UK: University of Exeter Press

(2012a). Literary Translation and the Rediscovery of Reading. Cambridge, UK: Cambridge University Press

(2012b). Translating the Perception of Text. Literary Translation and Phenomenology. London, UK: Legenda; Modern

Humanities Research Association and Maney Publishing

(2014). Translating Apollinaire. Exeter, UK: University of Exeter Press

(2018a). The Work of Literary Translation. Cambridge, UK: Cambridge University Press

(2018b). Translating Rhythm into the Rhythm of Translation. Comparative Critical Studies 15(3). Special Issue,

Thinking Language with Henri Meschonnic, ed. by Marko Pajević. 369-292.

Torop, P. Towards the semiotics of translation. Retrieved from

https://www.academia.edu/23477609/Towards the semiotics of translation

Venuti, L. (1995). The Translator's Invisibility. A History of Translation. London/New York: Routledge

\section{End Notes}

\footnotetext{
${ }^{1}$ It is, by the way, a shame that Scott hardly ever refers to the theory of Henri Meschonnic, even though at one instance he acknowledges Meschonnic's 'wonderfully enriching vision of translation' (Scott, 2018b, p.369). In the same article, however, he violently criticizes Meschonnic, mostly for not paying enough attention to the reader and not doing in his translations what he preaches. But Meschonnic's critique of the sign, his attention to the materiality of language, and his interpretation of notions such as rhythm or historicity are clear parallels between the two thinkers and have certainly been influential in Scott's thinking. Meschonnic (1932-2009) started developing his translation theory in the early 1970s. In English see Meschonnic (2011) and extracts in The Meschonnic Reader (Pajević, 2019).

${ }^{2}$ Karin Littau, amongst others, has also drawn in recent years attention to the role of materiality and mediality in translation, cf. f.ex. Littau, 2011 and 2016.

${ }^{3}$ With this, he probably refers to Richard Wagner's Gesamtkunstwerk and less to Peeter Torop's use of the term in his semiotics of translation, cf.

https://www.academia.edu/23477609/Towards_the_semiotics_of_translation.
} 